\title{
The effectiveness of biofeedback and neuromuscular stimulation on increasing endometrial thickness in patients undergoing frozen embryo transfer with thin endometrial thickness
}

\section{ARTICLE INFO}

Article Type

Analytical cross-sectional study

\section{Authors}

Mehri Nejat MD ${ }^{1,2 *}$,

Farah Akbarian $\mathrm{MD}^{3}$,

Elahe Hemmat Boland MS ${ }^{2}$

1 Faculty of Educational Sciences and Psychology, University of Tehran, Tehran, Iran.

2 Nejat Sexual Disorders Center Iran University of Medical Science, Tehran, Iran.

3 Sarem Fertility and Infertility Research Center (SAFIR), Sarem Women's Hospital, Iran University of Medical Sciences (IUMS), Tehran, Iran.
*Corresponding Author

Address: Agape Sexual Disorders Center \& Sarem Women Hospital, Basij Square, Phase 3, EkbatanTown, Tehran, Iran. Postal code: 1396956111 Phone: +98 (21) 44670888 \& +98 (21) 46040339

Fax: +98 (21) 44670432

mehrinejat8194@gmail.com

\section{ABSTRACT}

Objective: This study was performed to evaluate the effect of biofeedback and neuromuscular stimulation of pelvic floor muscles in improving endometrial thickness in women with thin endometrium.

Methodology: Of 62 women with a thin endometrium (less than or equal to $6 \mathrm{~mm}$ ) recommended for frozen embryo transfer, 32 underwent biofeedback and neuromuscular stimulation by a vaginal probe in addition to receiving routine treatment (as in the control group).

Findings: The women included in this study were 31 and 32 in the control and intervention groups. In general, the results showed that the endometrial thickness increased in each group, but in the group treated with biofeedback and neuromuscular stimulation, the thickness increased more. There was a significant difference between pre-treatment and post-treatment in increasing thickness. There is also a significant difference in the success rate of frozen embryo transfer between the two groups, which is higher in the group treated with biofeedback and neuromuscular stimulation. On the other hand, more in the intervention group, their pregnancy test was positive after the transfer of frozen embryos.

Conclusion: Treatment of functional electrical stimulation of the pelvic floor muscles can be effective in improving the increase in endometrial thickness.

Keywords: Infertility, Fetal Transfer, Frozen Fetus, Biofeedback, Neuromuscular Stimulation, Endometrial Thickness.

\section{Article History}

Received: March 05, 2020

Accepted: April 25, 2020

e Published: February 02, 2021

Copyright(C) 2021, ASP Ins. This open-access article is published under the terms of the Creative Commons Attribution-Noncommercial 4.0 International License which permits Share (copy and distribute the material in any medium or format) and Adapt (remix, transform, and build 
نتيجهَيرى: درمان تحريك الكتريكى عملكردى عضلات كف لكَن مى تواند در بهبود افزايش ضخامت آندومتر مؤثر باشد.

كليد وارْها: نازايى، انتقال جنين، جنين منجمد شده، بيوفيدبك، تحريك نوروماسكولار، ضخامت آندومتر

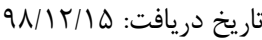
تاريخ خذيرش:

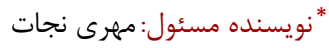

مقدمه

لانه گزينى جنين يك يديده يِيجيده و حاصل تعامل عوام جنينى و مادرى مارى

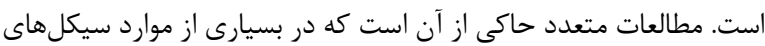
ناموفق IVF حاصل از جنينهاى نامطلوب و يا شرايط نامطلوب آندات آندومتر

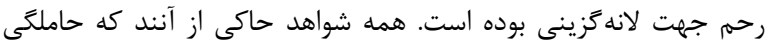

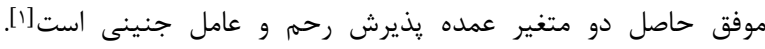
فاكتورهاى رحمى به طور مستقيم تعيين كننده موفقيت در درو باردارى

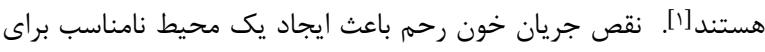

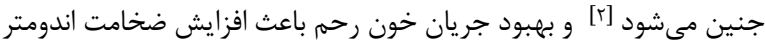

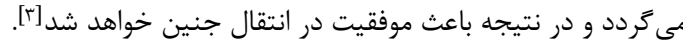

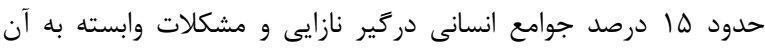

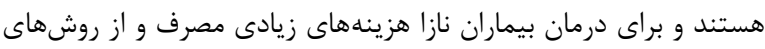

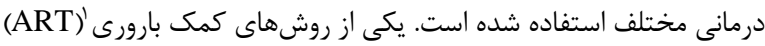

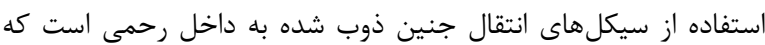

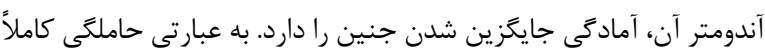

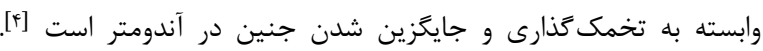

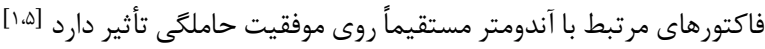

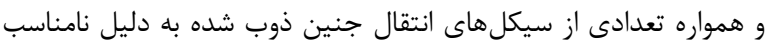

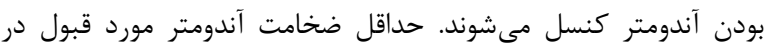

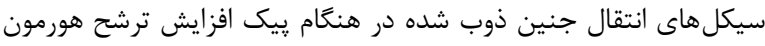

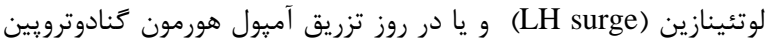

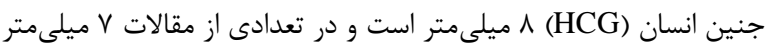

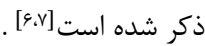

اثربخشى بيوفيدبك تحريك نوروماسكولار بر افزايش ضري آندومتر در بيماران كانديد انتقال جنين منجمد شده همراه با ضخامت آندومتر نازكى مهرى نجات اوץ *، فرح اكبريان "، الهه همت بلند ‘ ' دانشكده علوم تربيتى و روانشناسى دانشعاه تهران، تهران، ايران. rمركز تخصصى اختلالات جنسى نجات.

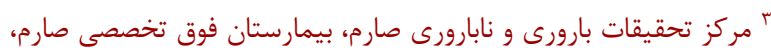

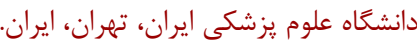

جكيده مقدمه: اين مطالعه به منظور بررسى تأثير بيوفيدبك و تحريك

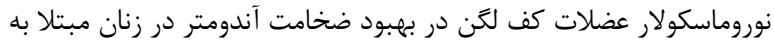
آندومتر ناز كى انجام كرديد.

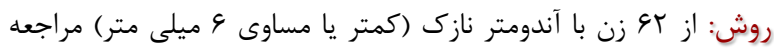

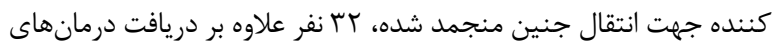

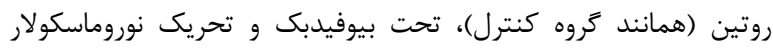
توسط يروب وازينال قرار كرفتند.

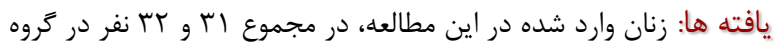

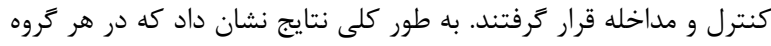

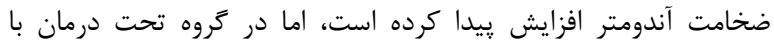

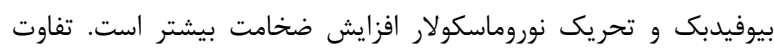

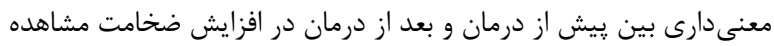

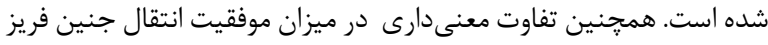

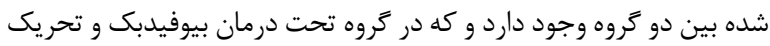

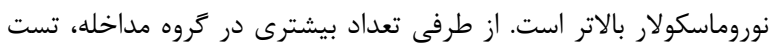

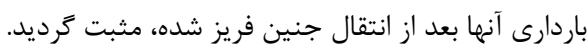

Assisted Reproductive Technology 
بيمارىهاى روانيزشكى شديد، و افتادگى وازَن بود. همه بيماران توسط

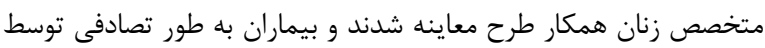

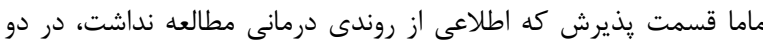

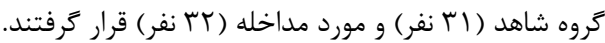

\section{آمادهسازى آندومتر}

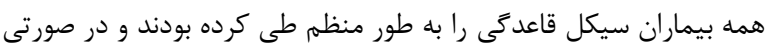

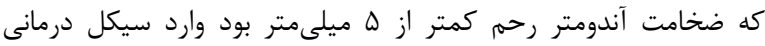

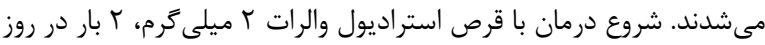

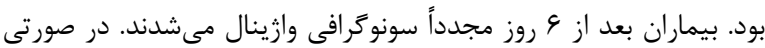

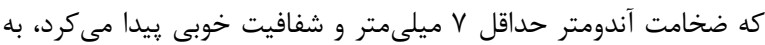

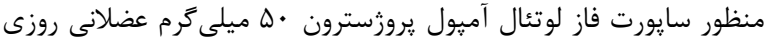

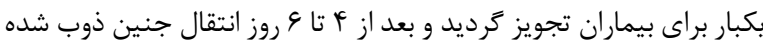

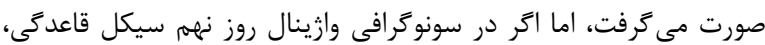

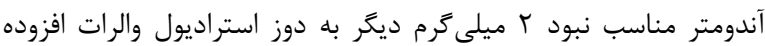

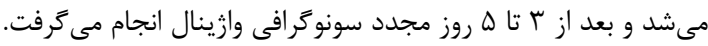

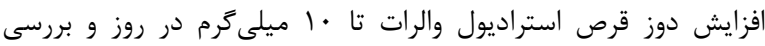

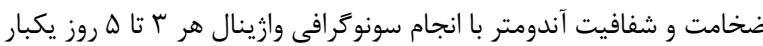

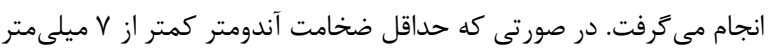

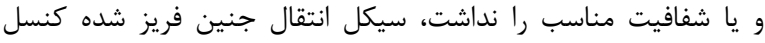

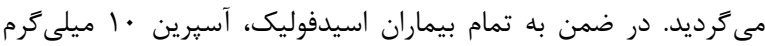

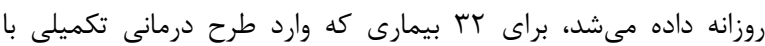

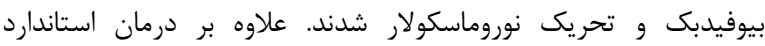
هورمونى، تحت درمان بيوفيدبك و تحريك نوروماسكولار به روش زيد ندير انجام

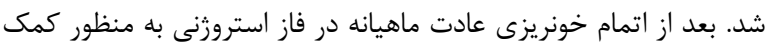

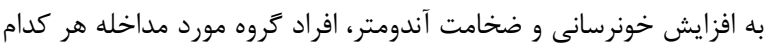
9 جلسه تحت بيوفيدبك و تحريك نوروماسكولار قرار تران ترفتند. بروتكل بيوفيدبك و تحريك نوروماسكولار به روش زير و توسط يك ماما داما

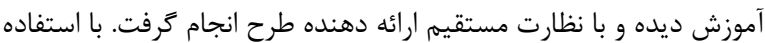

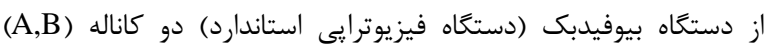

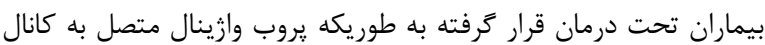

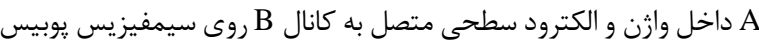

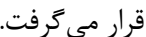

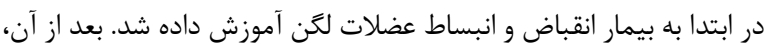

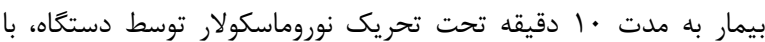

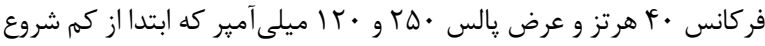

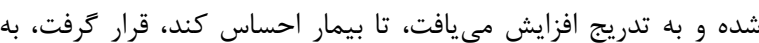

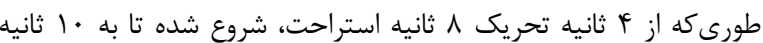

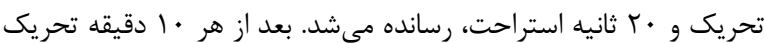

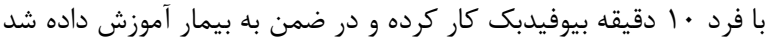

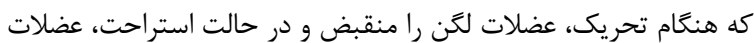

اخيراً تعدادى از محققين كه روى آنزيوزنز (رگزايى) و واسكولاريزاسيون

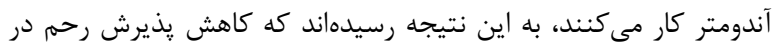

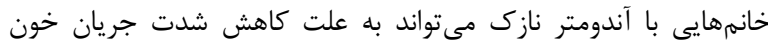

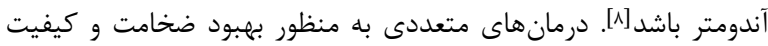

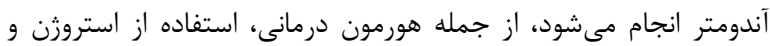
يروزسترون و اكونيستهاى هورمون آزاد كننده كَنادوترويين (GnRH)

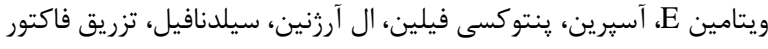

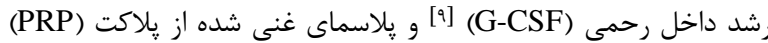

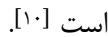

جند مطالعه بر روى اثر تحريك الكتريكى عصبى و عضلانى (NEMS) و و

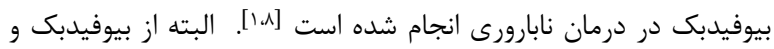

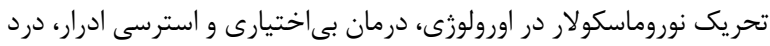

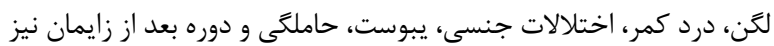

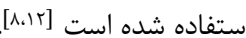

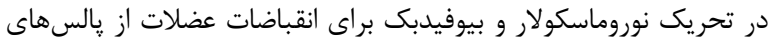

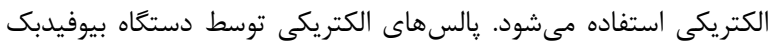

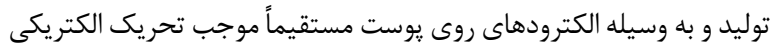

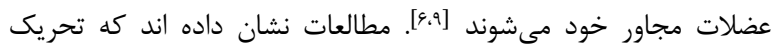

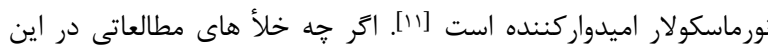

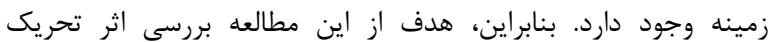

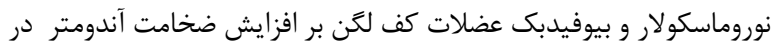

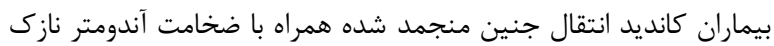

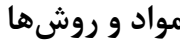

اين مطالعه توسط كميته اخلاقى دانشگاه علوم يزشكى ايران مورد تأييد

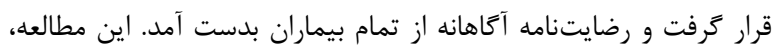

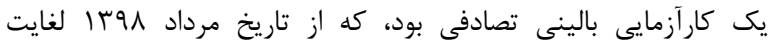

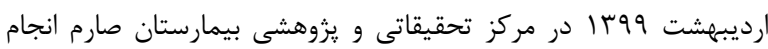

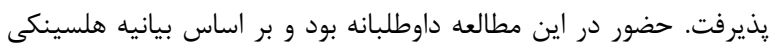

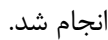
درمان هاى استاندارد آمادهازى آندومتر براى انتقال جنين ذوب شده براى

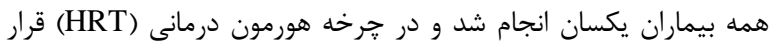

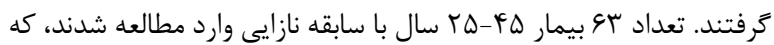

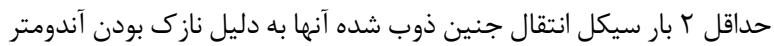

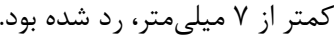

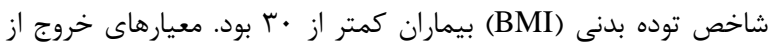

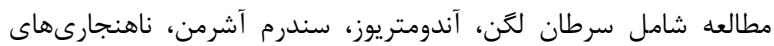

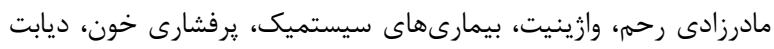

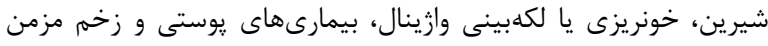
اطراف وارن ، ضربانساز قلب، آريتمى قلبى، اختلالات تشنج نايايدار و ورئي 
جدول 1. وضعيت شاخصهاى دموكرافيك

\begin{tabular}{|c|c|c|c|c|c|}
\hline \multicolumn{2}{|c|}{ 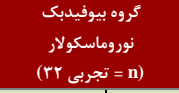 } & \multicolumn{2}{|c|}{ 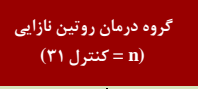 } & \multirow[t]{2}{*}{ 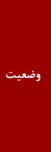 } & \multirow[t]{2}{*}{ شاخص } \\
\hline أنحراف معيار & تمعان* مينكي & انحراف معيار & يا ميانكين & & \\
\hline $9 / 19$ & $r N \mid Q T$ & $\Delta / r f$ & $r Y / \cdot \cdot$ & & سن (سال) \\
\hline s/9v & $191 / 4$. & $V / I r$ & $19 \cdot 119$ & & قد (سانتى متر) \\
\hline $1 \cdot 1 \cdot \Delta$ & 9N/DS & GND & $9 \mathrm{~V} / 94$ & & وزن (كيلو كرم) \\
\hline $9 / \Delta \mathrm{V}$ & $r / 9 \mathrm{~A}$ & $r / 49$ & $F / T \Delta$ & & مدت نازايى (سال) \\
\hline $\mathrm{VAN}$ & $r_{\Delta}$ & $\Lambda F / 9$ & r9 & خير & \multirow{2}{*}{ فيبروم رحه"، } \\
\hline$r / 9$ & $\mathrm{r}$ & 911 & $\Delta$ & بله & \\
\hline A1/N & 19 & $r \Delta / \Lambda$ & $\wedge$ & خير & \multirow{2}{*}{ بيمارى كيست تخمدان" } \\
\hline $1 / / \Lambda$ & 9 & $V \in \mathbb{K}$ & $r$ & بله & \\
\hline $99 / 9$ & $r$ & $\Delta r / 9$ & r9 & خير & \multirow{2}{*}{ مشكل لوله رحم" } \\
\hline$r / 1$ & 1 & 1911 & $\Delta$ & بله & \\
\hline SY/D & r. & $99 / 1$ & ri & خير & \multirow{2}{*}{ نازايى با علت مردانه". } \\
\hline$r V / \Delta$ & ir & $r / r$ & 1 & بله & \\
\hline$r 1 / 9$ & $\mathrm{r}$ & A.19 & $r_{\Delta}$ & خير & \multirow{2}{*}{ انتقال جنين فريز شده به رحمه" } \\
\hline $\mathrm{YAN} / \mathrm{I}$ & ro & $19 / 9$ & 9 & بله & \\
\hline TAMIT & 9 & $9 / 4 \Delta$ & $r$ & بله & \multirow{2}{*}{ باردارى بعد از انتقال (B-HCG) } \\
\hline$V / / A V$ & $r$ & $9 T / \Delta F$ & rq & خير & \\
\hline
\end{tabular}

همانكونه كه در جدول I مشاهده مىشود، ميانگين سنى (P=/ P99)

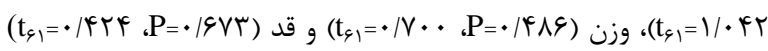

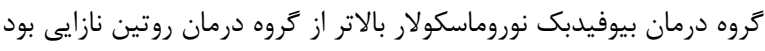

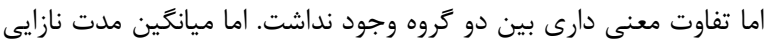

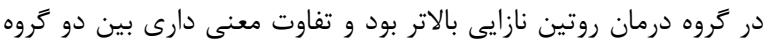

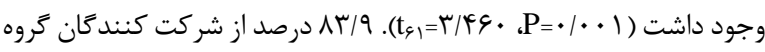

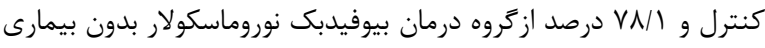

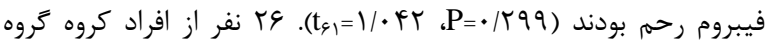

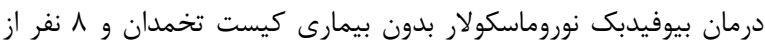

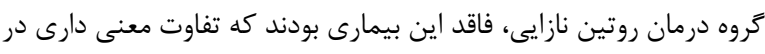

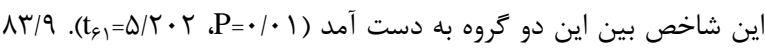

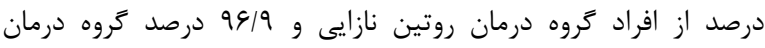

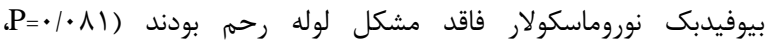
(t/9)=1/VV

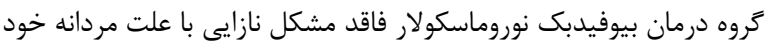

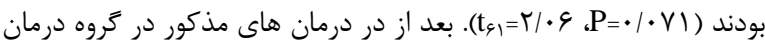

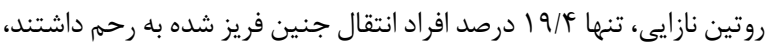

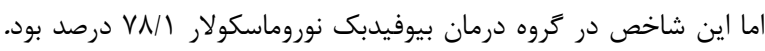

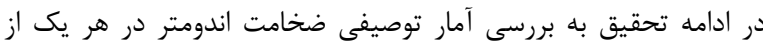

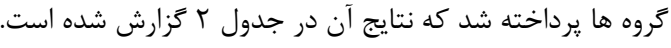

لكَن منبسط شود. در كل يك جلسه، بيمار •† دقيقه تحت تحريك

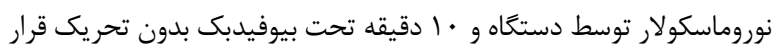

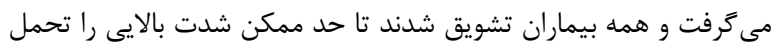

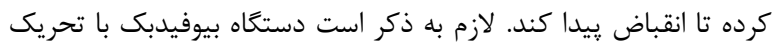

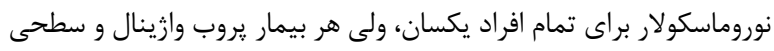

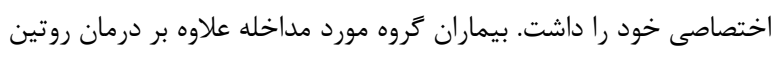

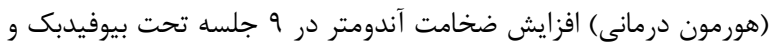
تحريك نوروماسكولار قرار خرفتند.

\section{آمادهسازى آندومتر}

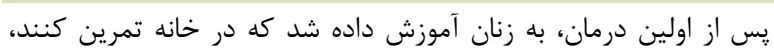

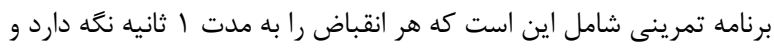

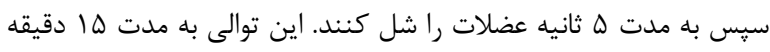

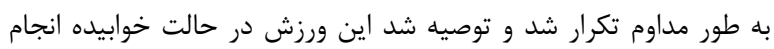

روش تحليل داده ها

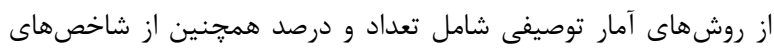

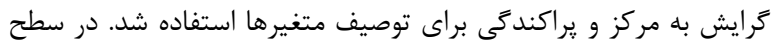

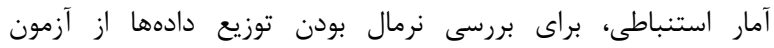

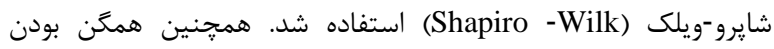

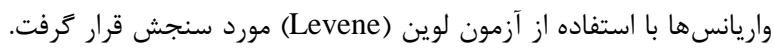

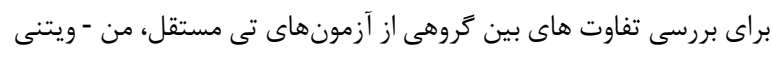

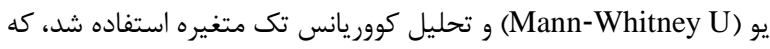

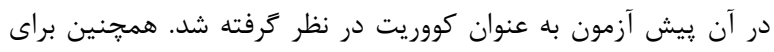

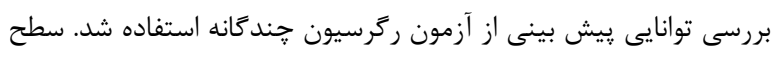

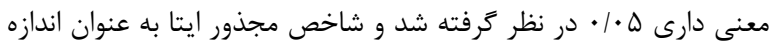

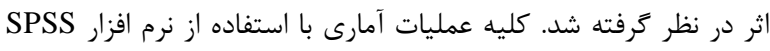
نسخه 91 انجام ترديد.

يافته ها جدول ا، نتايج مربوط به متغيرهاى دموكرافيك را بر اساس گروهها نشان مى دهد. 


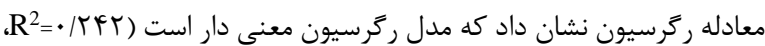

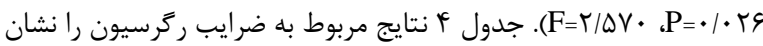

مى دهد.

جدول F. أبرايب ركر سيون در بيش بينى ضخامت اندومتر

\begin{tabular}{|c|c|c|c|c|c|}
\hline \multirow{2}{*}{ sig } & \multirow{2}{*}{$\mathrm{t}$} & استاندارد & \multicolumn{2}{|c|}{ ضرايب استاندارد } & \multirow{2}{*}{ شاخص } \\
\hline & & Beta & $\begin{array}{l}\text { Std. } \\
\text { Error }\end{array}$ & B & \\
\hline • $|r T|$ & $1 / \cdot 1$ & - & • /NA & $\cdot / 1 \Lambda F$ & مقدار ثابت \\
\hline • $/ 949$ & $-\cdot / \cdot V V$ & $-\cdot / \cdot 1$ & $\cdot|\cdot r|$ & $-\cdot / \cdot \cdot r$ & سن \\
\hline - /IFA & $1 / 4 \notin V$ & $\cdot / r \cdot 9$ & $\cdot / \cdot r V$ & $\cdot / \cdot \Delta F$ & مدت نازايى \\
\hline - /AVD & $\cdot / l \Delta \Lambda$ & . & $\cdot|\& \wedge|$ & $\cdot 1 \cdot$ VG & فيبروم رحم \\
\hline$\cdot / V \cdot 9$ & $-\cdot / r V \Delta$ &.$- \mid \cdot \Delta 1$ & $\cdot / r V \Delta$ & $-\cdot|| \psi \mid$ & كيست \\
\hline • /rᄉ & - |AV| & -.1119 & - IGTF & $-\cdot / Q F T$ & رشمل لوله \\
\hline$\cdot / 1 \cdot r$ & 1/994 & - & - / $A \Delta V$ & $\cdot / V \cdot 9$ & نازايى با علت \\
\hline$\cdot 1 \cdot 1 f$ & T/QFT & $\cdot / 4 \cdot T$ & 政 & $1 / 11$. & مداخله \\
\hline
\end{tabular}

همانكونه كه در جدول f مشاهده مىشود، هيج يك از شاخصها در حالت

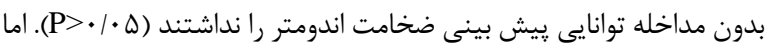

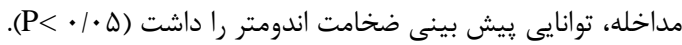

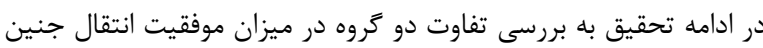

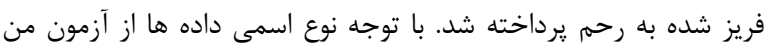

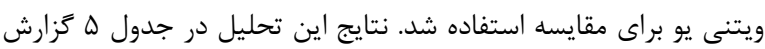

جدول ه. مقايسه موفقيت جنين انتقال داده شده به رحم در هر دو كروه

\begin{tabular}{|c|c|c|c|c|c|}
\hline sig & Z & $\begin{array}{c}\text { Mann- } \\
\text { Whitney U }\end{array}$ & جمع رتبه & ميانكين & كروه \\
\hline \multirow{2}{*}{$\cdot / . \cdot 1$} & \multirow{2}{*}{$-F / 9 r$} & \multirow{2}{*}{$r \cdot r / \Delta}$. & $|\pi| \Delta / \Delta$. & $41 / 11$ & كروروه ب بيوفيدبك \\
\hline & & & $\checkmark \cdots / \Delta$. & Tr/G. & نازايى درمان روتين \\
\hline
\end{tabular}

جدول r. توصيف آمارى ضخامت اندومتر در پِيش و پِ از درمان به

تفكيك كروه

\begin{tabular}{|c|c|c|c|c|c|}
\hline \multicolumn{2}{|c|}{ 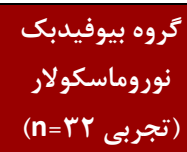 } & \multicolumn{2}{|c|}{ 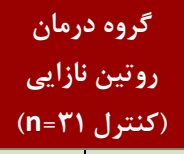 } & \multirow[t]{2}{*}{ وضعيت } & \multirow[t]{2}{*}{ شاخص } \\
\hline انحراف & ميانكين & معيار & يانكَين & & \\
\hline $1 / \cdot 1$ & $4 / 19$ & $1 / \cdot 9$ & T/qr & ديش برمان & \multirow{2}{*}{ ضدومتر رحم } \\
\hline I/Tr & $V / \cdot 1$ & $1 / \cdot r$ & $F / \Delta$. & درمان & \\
\hline
\end{tabular}

همانكَونه كه در جدول r مشاهده مى حشود در گروه هاى تحقيق از يِيش

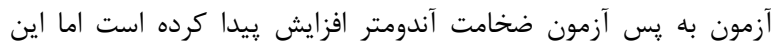

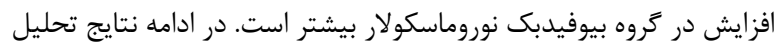

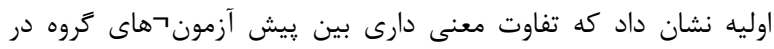

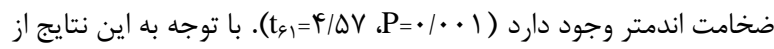

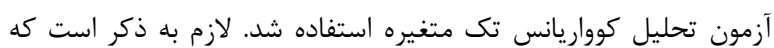

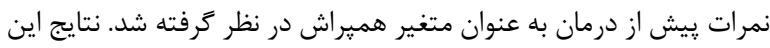
آزمون در جدول ب كزارش شده است.

جدول r. توصيف آمارى ضخامت اندومتر در پِيش و پِ از درمان به تفكيك كروه

\begin{tabular}{|c|c|c|c|c|}
\hline$n^{2}$ & sig & $F_{1-60}$ & منبع & شاخص \\
\hline$\cdot / 109$ & $.1 . .1$ & $11 / r V$ & پيش از درمان & \multirow{2}{*}{ ضخامت اندومتر } \\
\hline$\cdot / r \wedge \Delta$ & $.1 . .1$ & $r V|\varphi|$ & كروه & \\
\hline
\end{tabular}

همانكَونه كه در جدول r مشاهده مىشود، تفاوت معنى دارى در ضخامنت

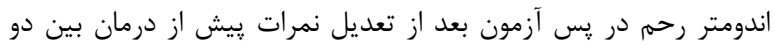

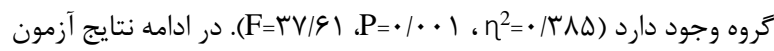

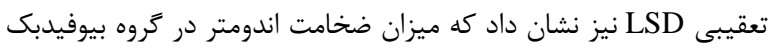

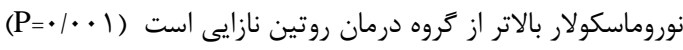

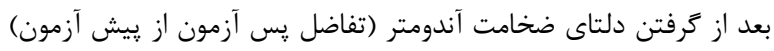

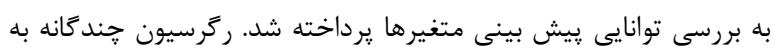

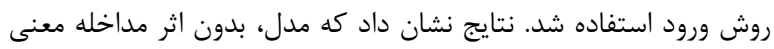

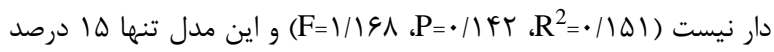

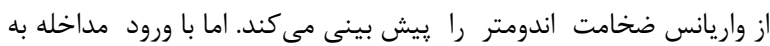


افزايش ضخامت آندومتر همم مىشود كه مطالعات متعددى نشان دهنده آن

است [19].

در يك مطالعه مشخص شده است كه با استفاده از بيوفيدبك و تحريك داسك

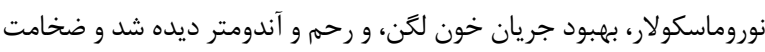

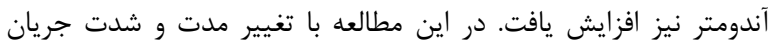

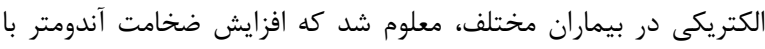

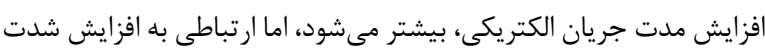

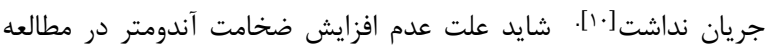

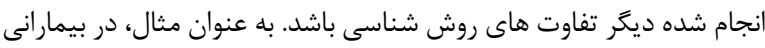

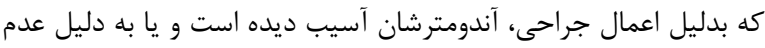

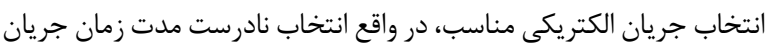

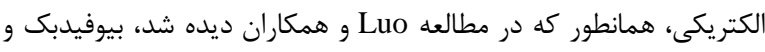

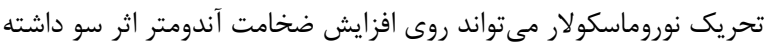

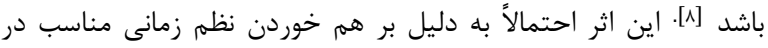
سيكل هاى انقباض و انبساط عضلات مى باشد.

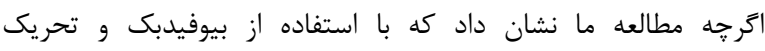

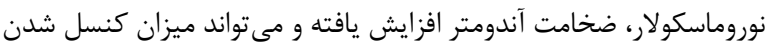

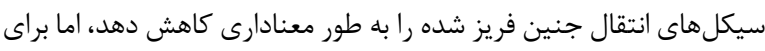

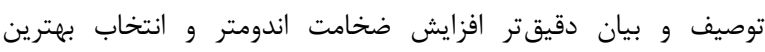

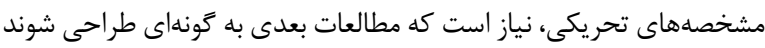

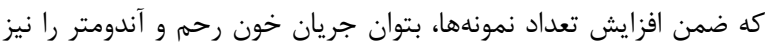

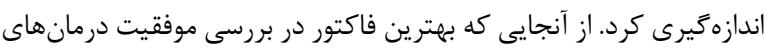

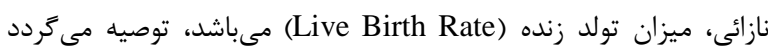

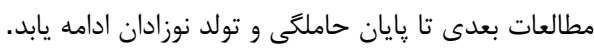

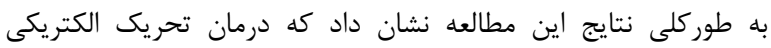

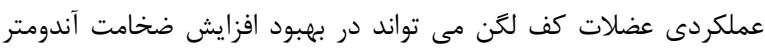

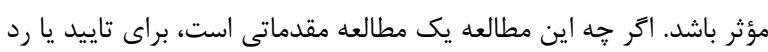

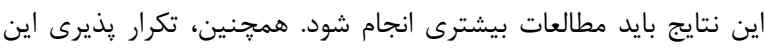
نتايج بايد با شركت كنندكان بيشترى انجام شود.

تشكر و قدردانى: بدينوسيله از جناب آقاى دكتر ابوطالب صارمى، آقاى دكتر محمد رضا ناطقى، سركار خانم نادرى و كاركنان محترم مركز

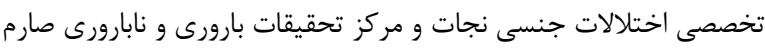
تقدير و تشكر به عمل مى آيد.

تاييديه اخلاقى: اين طرح مورد تاييد كميته اخلاق (IEC) مركز

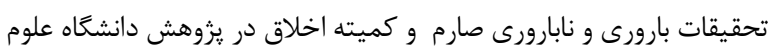

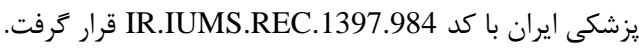
تعارض منافع: در اين مطالعه تعارض منافع وجود نداشت.
همانطور كه در جدول ه مشاهده مىشود، تفاوت معنى دارى در ميزان

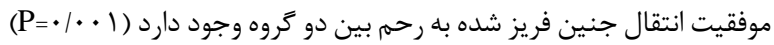

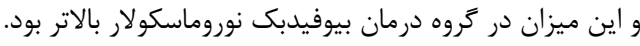

\section{بحث و نتيجه كيرى}

مطالعه ما نشان داد كه استفاده از بيوفيدبك و تحريك نوروماسكولار به

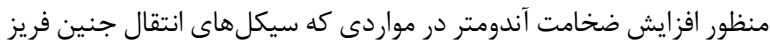

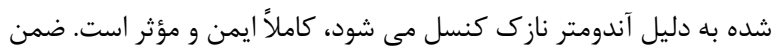

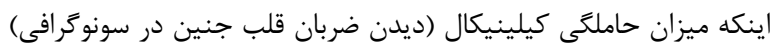

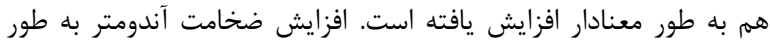

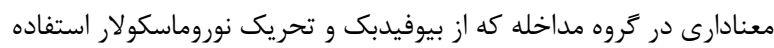

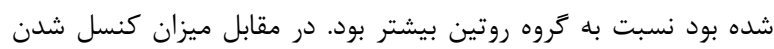

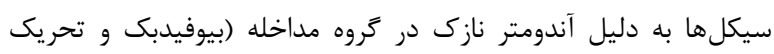

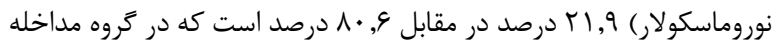

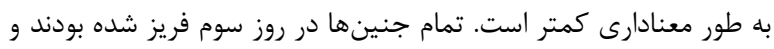

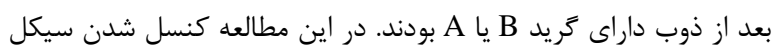

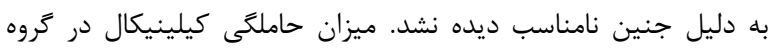

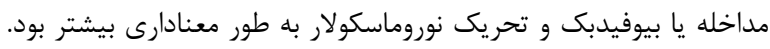

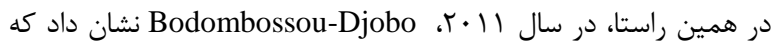

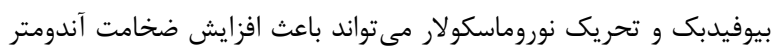

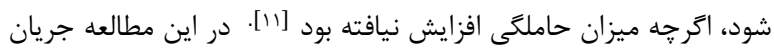

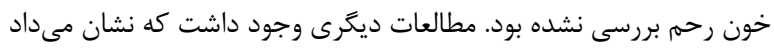

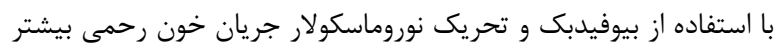

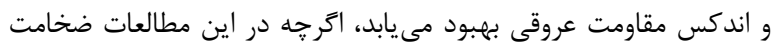

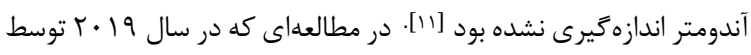
Luo

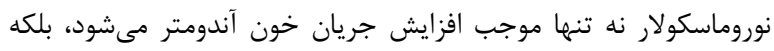

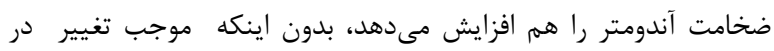

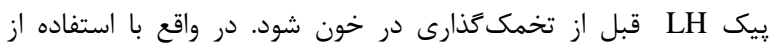

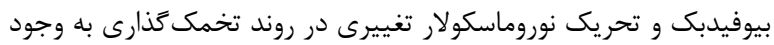

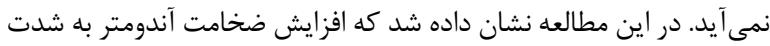

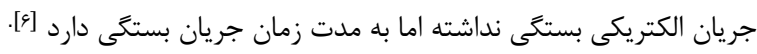

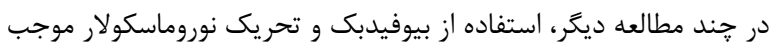

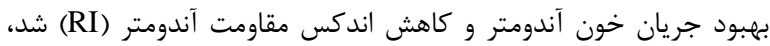

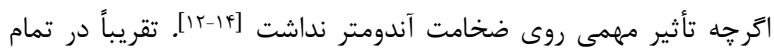

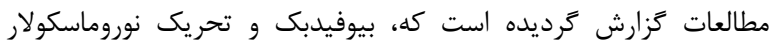

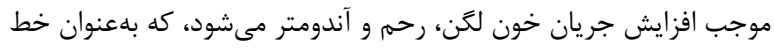

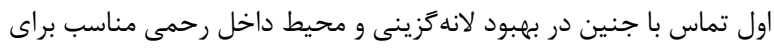

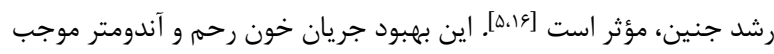


9- Lebovitz O, Orvieto R. Treating patients with "thin" endometrium-an ongoing challenge. Gynecological Endocrinology. 2014 Jun 1;30(6):409-14.

10- Zadehmodarres S, Salehpour S, Saharkhiz N, Nazari L. Treatment of thin endometrium with autologous platelet-rich plasma: a pilot study. JBRA assisted reproduction. 2017 Jan;21(1):54.

11- Bodombossou-Djobo MM, Zheng C, Chen S, Yang D. Neuromuscular electrical stimulation and biofeedback therapy may improve endometrial growth for patients with thin endometrium during frozen-thawed embryo transfer: a preliminary report. Reproductive Biology and Endocrinology. 2011 Dec;9(1):1-6.

12- Fall M, Baranowski AP, Elneil S, Engeler D, Hughes J, Messelink EJ, Oberpenning F, Williams AC. EAU guidelines on chronic pelvic pain. European urology. 2010 Jan 1;57(1):35-48.

13- Fink HA, Taylor BC, Tacklind JW, Rutks IR, Wilt TJ. Treatment interventions in nursing home residents with urinary incontinence: a systematic review of randomized trials. InMayo Clinic Proceedings 2008 Dec 1 (Vol. 83, No. 12, pp. 1332-1343). Elsevier.

14- Frydman R, Testart J, Giacomini P, Imbert MC, Martin E, Nahoul K. Hormonal and histological study of the luteal phase in women following aspiration of the preovulatory follicle. Fertility and sterility. 1982 Sep 1;38(3):312-7.

15- Dickey RP, Olar TT, Curole DN, Taylor SN, Rye PH. Endometrial pattern and thickness associated with pregnancy outcome after assisted reproduction technologies. Human Reproduction. 1992 Mar 1;7(3):418-21.

16- Zhong Y, Zeng F, Liu W, Ma J, Guan Y, Song Y. Acupuncture in improving endometrial receptivity: a systematic review and metaanalysis. BMC complementary and alternative medicine. 2019 Dec;19(1):1-9.
منابع مالى: اين طرح با هزينه محقق انجام يذيرفت.

منابع

1- Gupta SK. Embryo Implantation and Pregnancy: Immunologic Intricacies and Strategies for its Success. American journal of reproductive immunology. 2016 Mar;75(3):205-7.

2- Dören, M., Süselbeck, B., Schneider, H.P.G. and Holzgreve, W., 1997. Uterine perfusion and endometrial thickness in postmenopausal. women on long-term continuous combined estrogen and progestogen replacement. Ultrasound in Obstetrics and Gynecology: The Official Journal of the International Society of Ultrasound in Obstetrics and Gynecology, 9(2), pp.113-119.

3- Zeng X, Pang H, Li X, Luo S, Jin S, Li S. Impact of obesity on endometrial blood flow in women without polycystic ovarian syndrome during intracytoplasmic sperm injection. Reproductive Biology and Endocrinology. 2013 Dec;11(1):1-8.

4- Badreldin N, Kuller J, Rhee E, Brown L, Laifer S. Pregnancy management after bariatric surgery. Obstetrical \& gynecological survey. 2016 Jun 1;71(6):361-8.

5- Thouas GA, Dominguez F, Green MP, Vilella F, Simon C, Gardner DK. Soluble ligands and their receptors in human embryo development and implantation. Endocrine reviews. 2015 Feb 1;36(1):92-130.

6- Friedler S, Schenker JG, Herman A, Lewin A. The role of ultrasonography in the evaluation of endometrial receptivity following assisted reproductive treatments: a critical review. Human reproduction update. 1996 Jul 1;2(4):323-35.

7- Check JH, Cohen R, Choe JK. Failure to improve a thin endometrium in the late proliferative phase with uterine infusion of granulocyte-colony stimulating factor. Clin Exp Obstet Gynecol. 2014 Jan 1;41(4):473-5.

8- Luo YP, Xiao L, Liang JH, Lian W. Improvement of pelvic floor neuromuscular electrical stimulation (nmes) on endometrial thickness and blood perfusion of infertile women with thin endometrium. INTERNATIONAL JOURNAL OF CLINICAL AND EXPERIMENTAL MEDICINE. 2017 Jan 1;10(1):760-6. 